\title{
Correction to strength and symmetry of the third-order nonlinearity during poling of glass waveguides
}

Marckmann, Carl Johan; Jacobsen, Rune Shim; Ren, Yitao; Kristensen, Martin

Published in:

I E E E Photonics Technology Letters

Link to article, DOI:

10.1109/LPT.2002.801595

Publication date:

2004

Document Version

Publisher's PDF, also known as Version of record

Link back to DTU Orbit

Citation $(A P A)$ :

Marckmann, C. J., Jacobsen, R. S., Ren, Y., \& Kristensen, M. (2004). Correction to strength and symmetry of the third-order nonlinearity during poling of glass waveguides. I E E E Photonics Technology Letters, 16(8), 1987. https://doi.org/10.1109/LPT.2002.801595

\section{General rights}

Copyright and moral rights for the publications made accessible in the public portal are retained by the authors and/or other copyright owners and it is a condition of accessing publications that users recognise and abide by the legal requirements associated with these rights.

- Users may download and print one copy of any publication from the public portal for the purpose of private study or research.

- You may not further distribute the material or use it for any profit-making activity or commercial gain

- You may freely distribute the URL identifying the publication in the public portal 


\title{
Strength and Symmetry of the Third-Order Nonlinearity During Poling of Glass Waveguides
}

\author{
Carl J. Marckmann, Yitao Ren, Goëry Genty, and Martin Kristensen
}

\begin{abstract}
Negative thermal poling introduces second-order nonlinear effects into silica glass. The effects are studied using the charge separation model allowing for the third-order nonlinear effect to be anisotropic. The second-order nonlinear coefficient $\chi^{(2)}$ is found to be consistent with the results reported previously by Arentoft et al. (1999), Ren et al. (2002), and Marckmann et al. (2001) and the third-order nonlinear coefficient $\chi^{(3)}$ is found to be anisotropic but constant during poling.
\end{abstract}

Index Terms-Amorphous materials, electrooptic devices, electrooptic Kerr effect, electrooptic measurements, Pockels effect.

\section{INTRODUCTION}

$\mathbf{S}$ ILICA glass is an amorphous and, therefore, effectively a centrosymmetric material and thus does not exhibit a second-order nonlinear effect. This has prevented the development of nonlinear silica glass components such as electrooptic switches, modulators, tunable filters, and wavelength converters. In 1991, Myers et al. [2] succeeded in inducing a second-order nonlinearity in silica glass using thermal poling by which the silica glass is heated while a large static electric field is applied across it. UV poling was discovered in 1995 by Fujiwara et al. [3]. This represents another method for inducing a large second-order nonlinearity in silica glass. It is performed by applying a large static field across the sample while it is excited by UV irradiation. Unfortunately, the poling-induced second-order nonlinear effects are either too small to be used in components or difficult to reproduce. Therefore, a significant effort is put into achieving a large reproducible second-order nonlinear effect in silica glass. It has turned out that one of the keys to achieving this goal is to understand the properties of the third-order nonlinear effect.

\section{SAMPLE PREPARATION}

Our samples consist of an n-type silicon wafer with three glass layers deposited on top: the buffer layer (lower cladding layer), the core layer, and the top cladding layer. The buffer layer was made by thermal oxidation, the core and top cladding layers were made by plasma-enhanced chemical vapor deposition (PECVD). The core layer was doped with germanium and nitrogen. The germanium doping makes the core sensitive to

Manuscript received January 4, 2002; revised May 23, 2002.

C. J. Marckmann, Y. Ren, and M. Kristensen are with COM, Technical University of Denmark, Lyngby, Denmark (e-mail: cjm@com.dtu.dk; yr@com.dtu.dk; mk@com.dtu.dk).

G. Genty is with the Metrology Research Institute, Helsinki University of Technology, Helsinki, FIN-02015 HUT, Finland (e-mail: goery@cc.hut.fi).

Publisher Item Identifier 10.1109/LPT.2002.801595.
UV light [4]. Nitrogen doping was used for two reasons: First, nitrogen makes the poling more stable because it increases the charge trapping density in the interfaces between the core and cladding layers [5], [6]. Second, it is possible to make smaller components due to the larger refractive index step between core and cladding layers. Content estimation of the dopants yields $\sim 5.9$ atomic\% $(\sim 18.9$ molar\% $)$ Ge and $\sim 4.5$ atomic\% $(\sim 3.2$ molar\%) $\mathrm{N}$ [7]. After deposition of the glass layers and two-hour annealing at $800{ }^{\circ} \mathrm{C}$ in a nitrogen atmosphere, an aluminum mask was deposited on top of the glass layers defining straight waveguides. Deuterium loading was used to increase the UV sensitivity of the core layer [18]. By illumination of the sample with UV light from a $\mathrm{KrF}$ excimer laser, waveguides were made in the core layer. After deuterium out-diffusion and removal of the aluminum mask, Bragg gratings were made in the waveguides using a phase-mask [8]. The samples were annealed two times at $375{ }^{\circ} \mathrm{C}$ for $1.5 \mathrm{~h}$ to ensure that changes measured in the Bragg wavelength in the poling experiments were due to induced nonlinearities and not annealing effects. Finally, a top electrode was made with silver paste covering the region with Bragg gratings. The width of the top-electrode is $\sim 7 \mathrm{~mm}$, while the width of a waveguide is $\sim 7 \mu \mathrm{m}$. In all measurements, a waveguide was chosen approximately in the center of the top electrode in order to have an isotropic electric field across the waveguide. This, together with previous measurements showing almost no change in the dielectric constant as a function of applied UV fluence, indicates that fringe fields can be neglected.

\section{MEASUREMENTS}

In the measurements, light from an erbium-doped fiber amplifier (EDFA) or from a tunable laser was sent through a polarizer, polarization controller, then the sample(s) connected with an optical spectrum analyzer (OSA). ${ }^{1}$ Transmission spectra were recorded with different voltages applied across the sample(s) for both polarizations before and after poling. Typical transmission spectra are shown in Fig. 1. From the transmission spectra it is clear that the samples are at least double-moded (the modes denoted fundamental mode and higher order mode) due to the relatively large width of the UV written waveguides. There is birefringence in the samples due to stress in the grown layers as seen in the transmission spectra. Polarization dependent loss (PDL) for the two samples is low (PDL $\lesssim 1 \mathrm{~dB}$ ) and thus both polarizations were analyzed. Both modes of the samples were analyzed. Thermal poling of sample A2 was performed by heating the

\footnotetext{
${ }^{1}$ The polarizer was omitted when using the tunable laser due to its highly polarized output.
} 


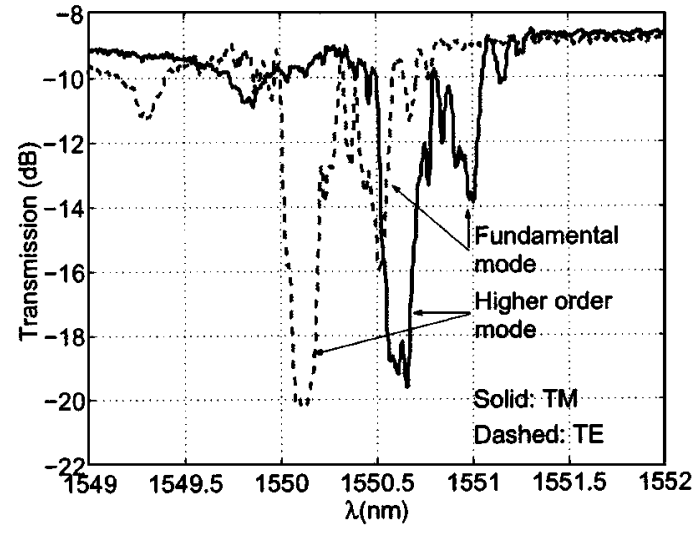

Fig. 1. Transmission spectra of sample A2.

sample to $375^{\circ} \mathrm{C}$ while applying $-2 \mathrm{kV}$ to the top electrode and grounding the silicon wafer. Sample A8 was poled by heating it to $357{ }^{\circ} \mathrm{C}$ with $-2.5 \mathrm{kV}$ applied across the sample in order to test the optimum poling parameters found by Ren et al. [9].

\section{THEORY}

By neglecting terms higher than second order in the electric field, $E$, across the sample, the change in refractive index $\Delta n$ can be expressed as a function of $E$

$$
\Delta n(E)=\frac{\chi^{(2)}}{n} E+\frac{3 \chi^{(3)}}{2 n} E^{2}
$$

where $\chi^{(2)}$ is the second-order nonlinearity and $\chi^{(3)}$ is the thirdorder nonlinearity [10]. Silica glass is a centrosymmetric material and thus $\chi^{(2)}$ is zero.

The mechanism of inducing a second-order nonlinearity $\chi_{\mathrm{eff}}^{(2)}$ in silica glass by electric field poling is not fully understood and two models exist [11].

\section{A. The Dipole Model}

In the dipole model, the induced second-order nonlinearity, $\chi_{\mathrm{eff}}^{(2)}$, is explained by a reorientation of dipoles in the glass during poling. As the sample cools down, the dipoles are frozen in according to the externally applied electric field. The realignment of dipoles orders the material, yielding a nonzero $\chi_{\text {eff }}^{(2)}$. According to Prasad and Williams [12] the reorientation of dipolar entities also yields a change in $\chi^{(3)}$ during poling.

\section{B. The Charge Separation Model}

In the charge separation model, it is assumed that mobile charges $\left(\mathrm{e}^{-}, \mathrm{Na}^{+}, \mathrm{Ag}^{+}\right.$, etc. $)$in the glass move toward the electrodes as the high voltage and the heating is applied. These charges will predominantly be trapped at the interfaces between the core and cladding layers, giving a sheet of charge on each side of the core layer with different polarity, yielding an internal field $E_{\text {int }}$ across the core layer. If an external field $E_{\text {ext }}$ is applied across the sample, the total field across the sample will be

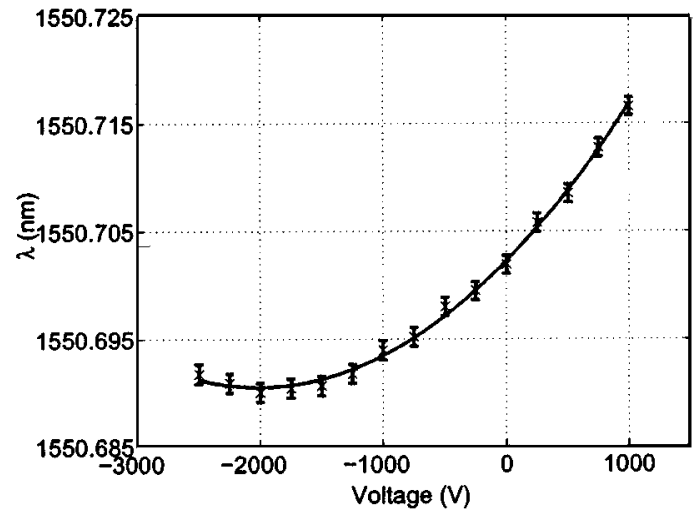

Fig. 2. The center values of the fundamental mode, TM polarization after poling, of sample A8 plotted versus the externally applied voltage and fitted to a parabola. The crosses represent the measured values and the vertical lines represent the experimental uncertainties.

TABLE I

Measured VAlues of $E_{\mathrm{int}}, \chi^{(3)}$, AND $\chi_{\mathrm{cff}}^{(2)}$ FOR SAMPLE A2

\begin{tabular}{|c|c|c|c|c|}
\hline & \multicolumn{2}{|c|}{ Before poling } & \multicolumn{2}{|c|}{ After poling } \\
\hline & TM & TE & TM & TE \\
\hline & \multicolumn{4}{|c|}{ Higher order made } \\
\hline$E_{i n t}\left(\frac{v}{\mu m}\right)$ & $0.5 \pm 1.3$ & $1.2 \pm 1.4$ & $116.4 \pm 1.1$ & $111.7 \pm 1.3$ \\
\hline$x^{(3)}\left(10^{-22} \frac{m^{2}}{V^{2}}\right)$ & $2.87 \pm 0.07$ & $2.27 \pm 0.05$ & $2.80 \pm 0.05$ & $2.35 \pm 0.05$ \\
\hline$x_{e f f}^{(2)}\left(10^{-3} \frac{p m}{V}\right)$ & $0.6 \pm 1.2$ & $0.7 \pm 1.0$ & $97.0 \pm 1.0$ & $78.8 \pm 1.0$ \\
\hline & \multicolumn{4}{|c|}{ Fundamental mode } \\
\hline$E_{i n t}\left(\frac{V}{\mu m}\right)$ & $-1.1 \pm 2.0$ & $-2.1 \pm 4.3$ & $87.8 \pm 3.4$ & $87.6 \pm 3.5$ \\
\hline$x^{(3)}\left(10^{-22} \frac{m^{2}}{v^{2}}\right)$ & $2.48 \pm 0.75$ & $1.61 \pm 1.04$ & $2.50 \pm 0.13$ & $2.29 \pm 0.13$ \\
\hline$x_{e f f}^{(2)}\left(10^{-3} \frac{p m}{V}\right)$ & $-0.7 \pm 1.5$ & $-1.0 \pm 2.0$ & $65.8 \pm 2.5$ & $60.1 \pm 2.5$ \\
\hline
\end{tabular}

$E=E_{\text {int }}+E_{\text {ext }}$. Inserting this expression into (1) and multiplying by the vacuum wavelength $\lambda_{0}$ yields the change in Bragg wavelength as a function of the electric field

$$
\begin{aligned}
\Delta \lambda(E) & =\frac{3 \lambda_{0} \chi^{(3)}}{2 n} E_{\mathrm{int}}^{2}+\frac{\lambda_{0} \chi_{\mathrm{eff}}^{(2)}}{n} E_{\mathrm{ext}}+\frac{3 \lambda_{0} \chi^{(3)}}{2 n} E_{\mathrm{ext}}^{2} \\
& =A+B E_{\mathrm{ext}}+C E_{\mathrm{ext}}^{2} .
\end{aligned}
$$

$A, B$, and $C$ are constants of a parabola. From these we can obtain the internal field $\left(E_{\text {int }}\right)$, the induced second-order nonlinearity $\left(\chi_{\text {eff }}^{(2)} \equiv 3 \chi^{(3)} E_{\text {int }}\right)$, and the third-order nonlinearity $\left(\chi^{(3)}\right)$

$$
E_{\mathrm{int}}=\frac{B}{2 C}, \quad \chi_{\mathrm{eff}}^{(2)}=\frac{n B}{\lambda_{0}} \quad \text { and } \quad \chi^{(3)}=\frac{2 n C}{3 \lambda_{0}} .
$$

\section{EXPERIMENTAL RESUlTS}

Allowing $\chi^{(3)}$ to be anisotropic, it is possible to analyze our measurements using the charge separation model. For each applied voltage, the transmission spectra are fitted with two Gaussian functions (one for each mode). The center of each mode is plotted versus the externally applied voltage and fitted to parabolas as seen in Fig. 2. Inserting the values of the constants $B$ and $C$ found from the curve fits into (2) yields the results presented in Table I for sample A2 and Table II for sample A8. 
TABLE II

Measured VALUeS of $E_{\text {int }}, \chi^{(3)}$, AND $\chi_{\mathrm{cff}}^{(2)}$ FOR SAMPLE A8

\begin{tabular}{|c|c|c|c|c|}
\hline & \multicolumn{2}{|c|}{ Before poling } & \multicolumn{2}{|c|}{ After poling } \\
\hline & $T M$ & $\frac{\text { TE }}{\text { Higher }}$ & $\begin{array}{c}\text { TM } \\
\text { ler mode }\end{array}$ & TE \\
\hline$E_{i n t}\left(\frac{y}{\mu m}\right)$ & $6.2 \pm 3.6$ & $-7.5 \pm 0.8$ & $180.4 \pm 6.9$ & $188.1 \pm 6.6$ \\
\hline$x^{(3)}\left(10^{-22} \frac{m^{2}}{V^{2}}\right)$ & $2.54 \pm 0.11$ & $1.68 \pm 0.14$ & $2.85 \pm 0.08$ & $1.95 \pm 0.07$ \\
\hline$\chi_{e f f(}^{(2)}\left(10^{-3} \frac{p m}{V}\right)$ & $4.7 \pm 2.7$ & $-2.5 \pm 3.4$ & $127.2 \pm 1.9$ & $110.3 \pm 1.5$ \\
\hline & & Fundarn & al mode & \\
\hline$E_{\text {int }}\left(\frac{V}{\mu m}\right)$ & $7.8 \pm 4.3$ & $-8.5 \pm 9.6$ & $178.2 \pm 7.8$ & $187.7 \pm 8.6$ \\
\hline$x^{(3)}\left(10^{-22} \frac{m^{2}}{v^{2}}\right)$ & $2.53 \pm 0.13$ & $1.71 \pm 0.20$ & $2.34 \pm 0.09$ & $1.88 \pm 0.08$ \\
\hline$x_{e f f}^{(2)}\left(10^{-3} \frac{p m}{V}\right)$ & $5.8 \pm 3.2$ & $-2.9 \pm 4.9$ & $125.8 \pm 2.2$ & $111.2 \pm 2.0$ \\
\hline
\end{tabular}

TABLE III

MEASURed $\gamma$-VAlues AfTer Poling For SAMPLes A2 AND A8

\begin{tabular}{l|c|c}
\hline & Sample A2 & Sample A8 \\
\hline Figher order mode & $1.24 \pm 0.02$ & $1.15 \pm 0.02$ \\
\hline Fundsmental mode & $1.09 \pm 0.06$ & $1.13 \pm 0.03$ \\
\hline
\end{tabular}

\section{DISCUSSION AND CONCLUSION}

According to the theory [13], one would expect that an isotropic media placed in a dc electric field would yield

$$
\gamma=\frac{\chi_{e f f, \mathrm{TM}}^{(2)}}{\chi_{e f f, \mathrm{TE}}^{(2)}}=3 .
$$

The $\gamma$ values calculated for the two samples after poling are listed in Table III. The values are close to 1.0. The significant discrepancy between the $\gamma$ from our experiments and that from the theoretical expectation is partially attributed to the anisotropy of the third-order nonlinearity as found in Tables I and II. Compressive stress ${ }^{2}$ and dispersion in $\chi^{(3)}$ are other possible explanations to the observed anisotropy. Further work is needed to make final conclusions to the origin of the anisotropic nature of $\chi^{(3)}$ observed in this letter.

The values found for the third-order nonlinearity are different from the values found by Liu et al. [14], [15] for bulk silica, $\chi^{(3)}=1.9 \cdot 10^{-22}\left(\mathrm{~m}^{2} / V^{2}\right)$, the reason probably being the heavy doping of our core layer [16].

The values of $\chi_{\text {eff }}^{(2)}$ found in this article are in accordance with the results previously reported by our group [1], [9], [17]. As seen from Table II of sample A8, the values of $\chi_{\text {eff }}^{(2)}$ obtained by poling using the optimized parameters found by Ren $e t a l$. [9] are a factor of $\sim 1.9$ larger than the induced $\chi_{\text {eff }}^{(2)}$ in a similar sample (sample $\mathrm{A}^{3}$ in Table I) poled under nonoptimized conditions. However, the symmetry properties are not significantly different.

The dipole model cannot explain our results because we could not observe a change in $\chi^{(3)}$ during poling within the experimental errors. However, a change is expected by the dipole

\footnotetext{
${ }^{2}$ From simulations the geometrical birefringence is found as $\Delta n_{\mathrm{cff}}^{\mathrm{gco}}=$ $n_{\text {off }}^{\mathrm{TF}}-n_{\mathrm{cff}}^{\mathrm{TM}} \sim 3.3 \cdot 10^{-4}$. Calculations following [19] and [20] yield that the stress-related birefringence is $\Delta n_{\mathrm{cff}}^{\text {stress }} \sim-9.7 \cdot 10^{-4}$ and thus the dominating birefringence term. From Fig. 1 it is found that the total birefringence is $\Delta n_{\text {cff }}^{\text {total }}=\Delta n_{\text {cff }}^{\text {gec }}+\Delta n_{\text {cff }}^{\text {stress }} \sim-4.8 \cdot 10^{-4}$ in fair agreement with the above mentioned birefringence terms.
}

${ }^{3}$ Sample A2 has previously been investigated in [17]. model. On the other hand, the $\gamma=3$ value as expected from the charge separation model is not fulfilled either.

In conclusion, we have found that the optimal poling conditions almost double the $\chi_{\mathrm{eff}}^{(2)}$. The measured $\chi^{(3)}$ is found to be anisotropic, contrary to the expectations for an isotropic material. Further work is in progress to elaborate on the origin of the anisotropy of $\chi^{(3)}$ and to increase the $\chi_{\text {eff }}^{(2)}$ effect to a level where it is possible to use silica-based electrooptic devices.

\section{REFERENCES}

[1] J. Arentoft, M. Kristensen, and J. B. Jensen, "Poling of planar silica waveguides," Proc. OSA TOPS, vol. 29, pp. 227-234, 1999.

[2] R. A. Myers, N. Mukherjee, and S. R. J. Brueck, "Large second-order nonlinearity in poled fused silica," Opt. Lett., vol. 16, no. 22, pp. 1732-1734, 1991.

[3] T. Fujiwara, D. Wong, Y. Zhao, S. Fleming, S. Poole, and M. Sceats, "Electro-optic modulation in germanosilicate fiber with UV-excited poling," Elecron. Lett., vol. 31, no. 7, pp. 573-575, 1995.

[4] K. O. Hill, Y. Fujii, D. C. Johnson, and B. S. Kawasaki, "Photosensitivity in optical fiber waveguides: Application to reflection filter fabrication," Appl. Phys. Lett., vol. 32, no. 10, pp. 647-649, 1978.

[5] D. Frohman-Bentchkowsky and M. Lenzlinger, "Charge transport and storage in metal-nitride-oxide-silicon (MNOS) structures," J. Appl. Phys., vol. 40, no. 8, pp. 3307-3319, 1969.

[6] D. Frohman-Bentchkowsky, "The metal-nitride-oxide-silicon (MNOS) transistor-Characteristics and applications," Proc. IEEE, vol. 58, pp. 1207-1219, Aug. 1970.

[7] J. Arentoft, "Poling of planar silica-based waveguides," Ph.D. dissertation, Research Center COM, Technical Univ. Denmark, Lyngby, Denmark, 2000.

[8] K. O. Hill, B. Malo, F. Bilodeau, D. C. Johnson, and J. Albert, "Bragg gratings fabricated in monomode photosensitive optical fiber by UV exposure through a phase mask," Appl. Phys. Lett., vol. 62, no. 10, pp. 1035-1037, 1993.

[9] Y. Ren, C. J. Marckmann, J. Arentoft, and M. Kristensen, "Thermally poled channel waveguides with polarization independent electro-optic effect," IEEE Photon. Technol. Lett., vol. 14, pp. 639-641, May 2002.

[10] B. E. A. Saleh and M. C. Teich, Fundamentals of Photonics. New York: Wiley, 1991.

[11] P. G. Kazansky and P. St. J. Russel, "Thermally poled glass: Frozen-in electric field or oriented dipoles?," Opt. Commun., vol. 110, pp. 611-614, 1994.

[12] P. N. Prasad and D. J. Williams, Introduction to Nonlinear Optical Effects in Molecules and Polymers. New York: Wiley, 1991.

[13] S. Kielich, "Optical second-harmonic generation by electrically polarized isotropic media," IEEE J. Quantum Electron., vol. QE-5, pp. 562-568, Dec. 1969.

[14] A. Liu, M. Digonnet, and G. Kino, "DC Kerr coefficient in silica: Theory and experiment," Proc. SPIE, vol. 3542, pp. 102-107, 1998.

[15] A. C. Liu, M. J. F. Digonnet, and G. S. Kino, "Measurement of the dc Kerr and electrostrictive phase modulation in silica," J. Opt. Soc. Amer. $B$, vol. 18, no. 2, pp. 187-194, 2001.

[16] D. L. Philen, D. W. Peckham, and I. Brener, "Measurement of the nonlinear index of refraction, $\mathrm{N}_{2}$, for various fiber types," in Proc. OFC 2000, vol. 37, 2000, pp. ThL5-1-ThL5-3.

[17] C. J. Marckmann, G. Genty, Y. Ren, J. Arentoft, and M. Kristensen, "Bragg gratings as probes to determine nonlinearities induced by thermal poling," in BGPP 2001, Tech. Dig., 2001, pp. BFC3-1-BFC3-3.

[18] P. J. Lemaire, R. M. Atkins, V. Mizrahi, and W. A. Reed, "High pressure $\mathrm{H}_{2}$ loading as a technique for achieving ultrahigh UV photosensitivity and thermal sensitivity in $\mathrm{GeO}_{2}$ doped optical fibers," Electron. Lett., vol. 29, no. 13, pp. 1191-1193, 1993.

[19] H. Vendeltorp-Pommer, "Numerical analysis of optical fibers with a noncircular symmetry in the refractive index profile," $\mathrm{Ph} . \mathrm{D}$. dissertation, Electromagnetics Inst., Tech. Univ. Denmark, Lyngby, Denmark, 1989.

[20] K. E. Mattsson, "Plasma-enhanced growth, composition, and refractive index of silicon oxy-nitride films," J. Appl. Phys., vol. 77, no. 12, pp. 6616-6623, 1995. 